\title{
El Progreso Médico y el Congreso de Berlín en 1890
}

\author{
WALTER LEDERMANN D.
}

\section{The medical progress and the Berlin meeting in 1890}

En junio de 1890 apareció en Chile El Progreso Médico, sumándose a la Revista Médica de Chile, que la superaba en dieciocho años y que perdura hasta nuestros días, y El Boletín de Medicina, del cual lo ignoro todo. "Es verdad que ya existen dos publicaciones de este jénero -advierten los flamantes editores- pero nosotros, aplaudiendo vivamente la obra por ellos realizada $i$ confiando en que sabrán llenar cumplidamente la que aun les reserva el porvenir, juzgamos, no obstante, que un periódico como el nuestro, por su forma i por su índole, vendrá a coadyuvar con un esfuerzo más..."1.

El Progreso Médico se definía como "órgano de medicina práctica" y estaba redactado por los doctores M. F. Aguirre, L. Asta-Buruaga, E. Cádiz, A. Costa Pruneda, A. Froemel, Cornelio Guzmán, Marcial Guzmán, V. Körner, G. Del Sol, E. S. Valenzuela, A. Vicencio y M. J. Barrenechea (sic), quien actuaba como Secretario de Redacción, con sede en Catedral 95. Este "periódico" se imprimía en la Imprenta Gutenberg, sita en Estado 38.

El Progreso Médico era esencialmente práctico y componíase casi exclusivamente de casos clínicos, presentados casi todos por los miembros del comité de redacción. Una sección importante era la Revista Estranjera, donde se reseñaban publicaciones europeas y es aquí, en el número de octubre de 1890, donde he encontrado esta perla: una reseña del Décimo Congreso Internacional de Medicina, celebrado entre el 4 y el 9 de agosto en Berlín, donde participaron, entre otros gigantes de nuestra entonces nonata especialidad, Robert Koch y Joseph Lister ${ }^{2}$.

Presidía este "evento" nada menos que el Pro- fesor Emérito Rudolph Ludwig Karl Virchow, próximo a los setenta años y en su máximo esplendor, "talvez -señala el Dr. Barrenechea-el genio más culminante de la medicina actual", el famoso patólogo enemigo de los gérmenes, de los cuales se expresara, en una frase para el bronce, como "esos seres mínimos que hoy despiertan la máxima atención”; el mismo que, con ocasión de la famosa comunicación de Koch a la Academia sobre el descubrimiento de su bacilo, guardó hosco silencio, retirándose luego sin un comentario ${ }^{3}$.

Hubo tres sesiones generales y veintidós secciones para presentación de trabajos, destinados a "más o menos 50 cuestiones para ser dilucidadas", a cuyo objeto se inscribieron 700 oradores. No está claro el número de asistentes: La semaine médicale hablaba de 5.000 y la Deutsche Medizinische Wochenschrift de 6.000, pues nunca estaban de acuerdo franceses y alemanes, pero un diario no médico, el Figaro de París, se remitió a la noticia pura y simple, señalando que eran 7.056. Es curiosa la clasificación que hace el diario de estos 7.056: miembros efectivos 5.561, participantes 116 ... y “mujeres" 1.379. Estimadas consocias, regocijaos de vivir en este siglo, porque en el XIX no hubierais podido participar en un congreso internacional como científicas o expositoras, sino como... mujeres.

La sesión inaugural tuvo lugar en el Circo Renz. ¡El circo! Quizás, después de todo, acaso sea el lugar más apropiado para más de un congreso médico... Las 22 secciones, en cambio, se hicieron en el Palacio de la Exposición. En las primeras sesiones inaugurales hablaron Lister y Koch; he creído interesante rescatar sus exposi- 


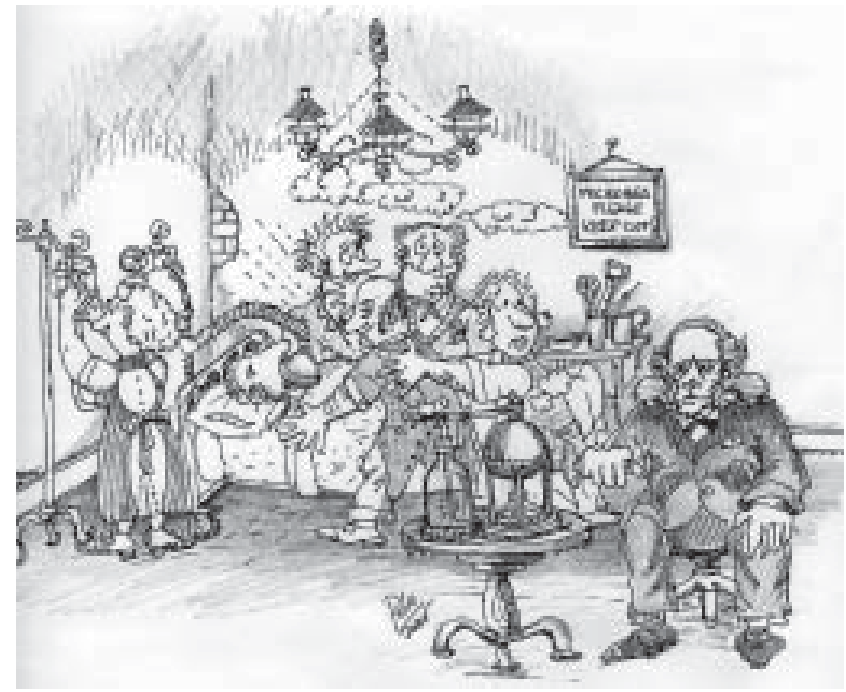

ciones más de cien años después. Pero antes, una pequeña joya: luego del discurso de Virchow, el secretario Lassar anunció que el Dr. Bayles comunicaría, a nombre de Edison, los resultados de sus experiencias sobre el tratamiento "electromecánico" de los cálculos...

Joseph Lister abrió el fuego con su conferencia Sobre el estado actual de la cirujía antisépti$c a$. Veamos la versión del Dr. Barrenechea: Desde el primer momento se declara (Lister) partidario de la teoría de Metschnikoff sobre la fagocitosis, i dice que solamente por esta teoría pueden esplicarse ciertos hechos hasta entonces inesplicables. Las células migratorias con movimientos amiboideos se nutren como los amibos, casi omnívoras por su apetito, tienen un gusto especial por los bacterios...(Noten mis lectoras el machismo: las amebas de hoy, eran amibos entonces, y las bacterias actuales, bacterios). Esta teoría esplica por qué motivo no se infecta la herida de la operación del labio leporino, bañada constantemente por la saliva, que contiene varias especies de bacterios sépticos. Los leucocitos que aparecen en la exudación fibrinosa destruyen estos bacterios.

Se extiende luego Lister en una horrorosa lista de antisépticos. Dice que las esponjas usadas en cirugía de abdomen deben desinfectarse en ácido sulfúrico. Para "el resto del cuerpo" prescribe una solución "débil" de sublimado (bicloruro de mercurio) al 1 por 10.000 , que puede concentrarse al... i1 por 500 ! para el lavado de las heridas. Aclara, eso sí, que en las articulaciones no usa "soluciones antisépticas fuertes, para evitar las irritaciones de la sinovial".

El punto crucial de la conferencia y de la discusión se centra en los gérmenes del aire. Lister hace un mea culpa: "En cuanto al pulverizador, me siento avergonzado de haberlo recomendado antes para destruir los microbios del aire, creencia que pudo llevarme a descuidar tal vez otros detalles del método antiséptico". En la conferencia siguiente, repartida a todos los concurrentes en versiones en distintos idiomas, el Profesor Von Bergmann expresó que en su clínica usaba desde hacía varios años la asepsia en lugar de la antisepsia, pues la infección por aire se producía rara vez. En la versión española dice que "el polvo con jérmenes que cae del aire está mui breve tiempo en contacto con la herida abierta, no teniendo por lo mismo, en jeneral, influencia nociva".

Para entender toda la humildad del mea culpa de Lister debemos rebuscar en viejos textos de antisepsia. Uno de ellos ${ }^{4}$ se refiere extensamente a le spray ( $\mathrm{sic}$ ) y cuenta que primero Lister quiso proteger el campo operatorio usando grandes compresas aceitosas, que resultaron incómodas y por completo carentes de eficacia. Entonces ensayó envolver el campo operatorio en una fina nube de una solución de ácido fénico pulverizado, que era más bien una aspersión, método muy criticado porque "mojaba las heridas; era desagradable para la respiración del operado, del 
cirujano y de sus ayudantes; precipitaba aún más los gérmenes sobre la herida operatoria, al crear fuertes corrientes de aire; y causaba accidentes por intoxicación".

La necesidad crea el hábito y Lister devino en ingeniero improvisado, diseñando un pulverizador a vapor, con el que obtuvo un producto fino, regular y que no mojaba. El aparato tenía un reservorio esférico, resistente a altas presiones, que actuaba a manera de caldera y en el cual el agua se calentaba mediante una lámpara de alcohol, fija, no desplazable por accidente, y de intensidad regulable. Por cierto que la pequeña caldera tenía en su parte superior una válvula de seguridad, para evitar explosiones, y un sistema de aislamiento en madera, para poder trasladar todo el aparato sin quemarse los dedos. Una serie de mangueras y conexiones mezclaban con el vapor de agua una solución al 5\% de ácido fénico. Todo el secreto del éxito radicaba en la aguja que diseñara Lister, por donde el vapor, al pasar a presión, se pulverizaba finamente. La máquina se ponía a dos metros del campo operatorio, al cual bañaba con un tenue tinte azul.

Con el tiempo, sin embargo, Lister se desengañó y abandonó su querido pulverizador, reemplazándolo por una serie de géneros empapados en soluciones antisépticas, distribuidos sabiamente alrededor de la herida operatoria, en tanto que sobre la misma disponía algodón purificado, evitando que se humedeciese, pues entonces la infección del aire podía llegar fácilmente hacia los tejidos.

En todo caso, el profesor Von Bergmann pulverizó a Lister. No sólo entregó su conferencia escrita y traducida: también llevó a algunos congresales a visitar su famosa clínica, donde les mostró los procedimientos empleados en varios enfermos, así como un esterilizador de toallas y paños, diseñado por Rietschel y Henneberg de acuerdo a los principios de Robert Koch... Todos alemanes, como puede verse, según el dicho imperante en la época: si es alemán, es bueno. Además, estaban en Berlín...

Debo reconocer que la conferencia de Koch - El estado actual de la bacteriolojía- me ha parecido bastante deslucida ${ }^{5}$. El mismo parece haberse dado cuenta de la debilidad de su exposición, reconociendo que es un tema muy conocido y que, para no hacerlo tan árido, anuncia que agregará algunas de sus experiencias en tuberculosis. Tiene, no obstante, algunos puntos rescatables. Basa el éxito y el rápido desarrollo de la bacteriología en tres hechos: el perfeccionamiento del microscopio, los nuevos métodos de coloración con anilinas y los cultivos en medios sólidos, que han permitido descubrir nuevos bacterios causantes de enfermedades. Y aquí viene, emulando a Lister, su frase de humildad: Se esperaba encontrar el bacterio correspondiente a cada enfermedad infecciosa, pero ello no ha sido posible. Otra renuncia a su orgullo es el reconocimiento de los logros de Pasteur, su tradicional e irreconciliable rival, en el terreno de las inmunizaciones.

Parece que la fagocitosis era el tema del momento. Koch dice que esta teoría "pierde terreno" ante el avance que han tenido los estudios del parasitismo bacteriano, del modo de penetración y evolución dentro del organismo por los microbios, de los productos químicos que resultan de su interacción ("las toxo-albúminas"), etc. En la conferencia siguiente, Mecanismo de la infección $i$ de la inmunidad, el francés Bouchard refuta al alemán y reinvindica el fagocitismo. Para este sabio, la inmunidad consta de dos medios poderosos de defensa; el uno resulta de una condición estática, es decir química, del organismo, llamado "estado bactericida"; el otro está asegurado por una condición dinámica, por la participación de la vida, por la actividad celular, es el "fagocitismo". Allí los glóbulos blancos salen por diapedesis de los vasos para apoderarse de los microbios y devorarlos. Estos dos medios obran simultáneamente en la defensa del organismo; tomados aisladamente no son capaces de garantir o de restablecer la integridad del organismo.

Bellas palabras, hermoso lenguaje médico de antaño, hoy perdido en medio de unas frases hechas, mecánicas: se ha comprobado que, numerosas publicaciones indican, varios metanálisis concluyen...iQue contraste con "por la participación de la vida" y los leucocitos saliendo de los vasos "para apoderarse de los microbios y devorarlos”! ¡Qué dirían los editores de nuestra revista si les enviara un caso clínico describiendo cómo "la vancomicina se precipitó tumultuosamente por los vasos, dinamitando la pared de los estafilococos!"

El Congreso fue muy lucido. Con orgullo infectológico, pude comprobar que los dos campos principales, que acapararon las sesiones magnas, fueron las enfermedades infecciosas y la neurología, en este orden. No me queda claro si alguna de las cincuenta cuestiones a dilucidar pudo aclararse, pero lo dudo.

Poco después de este Congreso, en el número de diciembre de 1890, El Progreso Médico analizó, en la misma sección de Revista Estranjera, la Nueva comunicación sobre un tratamiento de la tuberculosis ${ }^{6}$, en el cual Robert Koch hablaba de 
un líquido transparente, que no sólo era una excelente herramienta para el diagnóstico, sino que hacía también maravillas en los tejidos devastados por el Mycobacterium. Aunque no daba nombres, se trataba de la tuberculina, el sonado fracaso terapéutico que terminaría por erosionar peligrosamente su fama.

Ignoro cuán larga fue la vida de El Progreso Médico. Tengo en mi biblioteca hasta el número de diciembre de 1894, en que los editores eran ya más numerosos, habiendo aparecido un segundo comité editorial en Valparaíso, y en cuya sección Revista Estranjera se analiza un artículo de Katz, que me ha dejado perplejo. Publicado en el Munch Med Wochensch el 3 de julio de 1894, cuenta el tratamiento de 128 niños diftéricos con "la antitoxina de Aronson". ¿Aronson ? Escucho a Emile Roux y a von Behring rebullirse, inquietos, en sus tumbas. Pero, tranquilos, que dicha antitoxina no era muy buena: apenas redujo la mortalidad del 37 a 13 por ciento 7 .

Una cosa lleva a la otra. Aunque fueron muchos y valiosos los aportes de Roux al desarrollo de la antitoxina, fue von Behring quien por primera vez mencionó el término en un paper y quien impuso e implementó esta herramienta terapéutica, lo cual le valió el Premio Nobel en 1901. Y aquí nos topamos de nuevo con el Profesor Von Bergmann, el mismo que en párrafos anteriores vimos refutando la antisepsia de Lister, porque fue en su clínica de Berlín, aquélla donde invitara a algunos congresales a conocer la asepsia en el terreno, el lugar escogido para aplicar su antitoxina por primera vez a un niño con difteria, en la Navidad de 1891, según relata Wernicke ${ }^{8}$.

¿Cómo se recordarán nuestros congresos en cien años más ?... iSe celebraban en los hoteles!
¡Analizaban largas listas de horrorosos antibióticos! O, quizás, alguien más atinado que este pobre cronista será capaz de reconocer que, en suma, el Congreso de Berlín de 1890 y el de Chicago de 2100 no difieren sino en las formas, persistiendo a través del tiempo las discursivas conferencias magistrales, las lógicas discusiones entre los científicos, las posturas irreconciliables de algunos famosos y... las "cincuenta cuestiones" todavía sin dilucidar.

Y sin duda, como ahora, en el futuro la audiencia se dividirá entre expositores, invitados, asistentes y acompañantes: ya nunca más habrá "mujeres".

\section{Bibliografía}

1.- La redacción. Dos palabras. El Progreso Médico 1890. I (1): 1-3.

2.- Barrenechea M J. El Décimo Congreso Internacional de Medicina en Berlín. El Progreso Médico 1890, I (5): $112-6$

3.- Ledermann W. Franceses y alemanes tras la etiología de la tuberculosis. Rev Chil Infect 1994; 11: 239-42.

4.- Le Gendre, Barette et Lepage. Pulvérisation antiseptique. Le spray. Traité pratique d'antisepsie appliquée a la thérapeutique et a l'hygiène. Steinhel, Libraireéditeur, Paris 1888; pp: 73-7.

5.- Barrenechea M J. X Congreso internacional de Medicina de Berlín. Primera sesión jeneral. Koch. El Progreso Médico 1890, I (6): 136-41.

6.- Koch, R. Nueva comunicación sobre un tratamiento de la tuberculosis. (De la "Semaine Medicale" del 15 de noviembre, número especial). El Progreso Médico 1890; I (7): 161-8

7.- Katz. Tratamiento de la difteria por la antitoxina de Aronson (traducción). El Progreso Médico 1894; IV (12): 388-90.

8.- Wernicke, E. Diphtherie (Halsbräune). Handbuch der pathogen Mikroorganism. Zweite Auflage. Herausgegeben von Kolle und Wassermann, Hamburg 1913; B 5: 1011 . 